\title{
DEMOCRACIA, DERECHOS HUMANOS Y LEGITIMIDAD POLÍTICA
}

\section{Fabio Lara Cerón ${ }^{1}$}

Tnicio este documento haciendo énfasis en que la historia es una ciencia eminentemente toral en el conocimiento de un país, mismo que para su cabal desarrollo, requiere de una paz debidamente consensada, no impuesta, donde la correcta aplicación de la justicia garantice la seguridad jurídica en bien de un pueblo, porque es evidente que en los países donde se han asentado diversos grupos humanos — con diferentes culturas e intereses_- se corre el riesgo de que no haya una armoniosa relación entre los gobernantes y gobernados, puesto que no siempre se genera un ambiente de cordialidad y equilibrio entre todos los sectores sociales de los estados o países.

Algunas de las causas de estas disociaciones de las sociedades pueden ser porque no están satisfechas con la forma de elección de sus gobernantes, por la extensión de sus territorios, o por la invasión de éstos en virtud de que se encontraban en una etapa de consolidación- o porque, al existir diversidad de culturas y conflictos de intereses, se ven en la necesidad de recurrir a las guerras para seguir conservando su territorio, su forma de gobierno, su cultura y todo vínculo de identidad que los hace ser unidos y constituirse como una nación autónoma, libre e independiente, con gobiernos propios que les permitan otorgar a todos y cada uno de sus gobernados la plena satisfacción de sus necesidades y legítimas aspiraciones.

Lo anterior, porque esos grupos sociales han sido partícipes de un devenir histórico derivado de un proceso democrático, pacífico y transparente en el cual imperó la legalidad en bien de toda una colectividad,

1 El autor es Maestro en Derecho Constitucional y Amparo por la Universidad Autónoma de Tlaxcala, y Director de la Facultad de Derecho, Ciencias Políticas y Criminología de la Universidad Autónoma de Tlaxcala 
dando así la oportunidad para que los gobernantes ejerzan y desarrollen sus funciones de manera adecuada, apegadas a la ley, sin actos de corrupción, de injusticia, tiranía o traición a la patria.

Por tan loables razones, es sumamente importante el estudio de la democracia, porque por medio de ella se determinan las formas de gobierno, y en particular por las que nuestro México ha transitado en su definición del rumbo y consolidación como país.

Es así que me permito hacer una semblanza muy sintetizada del tema de la democracia, en el marco de esta obra que honra la trayectoria de uno de nuestros más connotados académicos y líderes intelectuales, el Dr. Serafín Ortiz Ortiz.

\section{Historia y legitimación política}

La historia de nuestro México se ha escrito por épocas en las cuales se han destacado inteligentes y valientes patriotas mexicanos que han pasado a la gloria de la inmortalidad, gracias a sus trascendentales acciones y justas heroicas, derivadas de sus firmes principios, convicción nacionalista, patriotismo acendrado y preocupación por el bienestar o prosperidad y seguridad de una colectividad, siendo todo esto el punto de partida, la causa fundamental o el fin último por el que se defiende la estabilidad, independencia y desarrollo — aun cuando por ello se generen movimientos políticos, sociales y hasta movimientos armados, en los que se han sacrificado un incalculable número de vidas de seres humanos, principalmente de los sectores sociales más desprotegidos.

Es así que estos próceres, en aras de obtener un mejor nivel de vida para sí y los suyos, han sido sujetos de verdaderas hecatombes sociales, que al paso del tiempo la historia nacional — por su singular importancia- las registra como actos heroicos, inmortalizando la acción de quienes participaron en ellas, dando cuenta de esas hazañas en célebres páginas que quedan para el loor eterno de las generaciones presentes y futuras, quienes de manera directa e indirecta reciben sus beneficios.

Desde los años 1325 a 1519, gobernados por una línea dinástica de emperadores, los aztecas tuvieron 194 años de esplendor; empero, con la llegada de Hernán Cortés y sus huestes, se desarrolla la conquista de Mé- 
xico que concluye con la toma de Tenochtitlan el 13 de agosto de 1521, iniciándose a partir de esa fecha una nueva forma de gobierno, siendo representada por el Capitán General y Justicia Mayor Hernán Cortés; posteriormente, la de Capitán General y Gobernador de la Nueva España que recayó en él mismo hasta 1524; posteriormente, al periodo de 1524 a 1526, se le conoce como el gobierno de los «oficiales reales». Y en el lapso de 1526 y 1527, hubo la designación de varios gobernadores provisionales de la Nueva España, hasta que en 1528 se instituye el gobierno de Audiencias, siendo nombrados sus integrantes por la Corona española, durando este tipo de gobierno hasta 1535; finalmente, por los abusos cometidos por tales Audiencias, sobre todo por la primera, a partir de 1535 y hasta el año de 1821 se estableció el Virreinato para la Nueva España, habiendo existido un total de 63 virreyes, 62 de ellos nombrados por el Rey de España, a excepción del penúltimo que fue de facto, y muy breve en su función Don Francisco de Novella, quien fue nombrado por una Junta Militar.

A partir del año 1821, al inicio de nuestra independencia formalizada luego de la firma de los Tratados de Córdoba-, se tuvo un emperador y un triunvirato; una vez promulgada la Constitución Federal de los Estados Unidos Mexicanos en 1824, se habilitó una forma de gobierno republicano y federal, pero al realizarse el cambio de poderes hubo una pugna nuevamente entre los bandos centralistas y federalistas, de donde surgió otro triunvirato; posteriormente, siendo presidente Antonio López de Santa Anna, por medio de la promulgación de las Siete Leyes, se estableció un gobierno centralista, y durante todo el tiempo que gobernó Santa Anna, existió la pugna entre liberales y conservadores, situación que originó un nuevo Congreso Constituyente, del cual surgió la Constitución Política de la República Mexicana de 1857.

En los años siguientes, se dio la existencia de dos formas de gobierno: uno republicano y otro monárquico, con Benito Juárez y Maximiliano de Habsburgo, respectivamente; luego, a la muerte de Juárez (que había reducido al enviado europeo en Querétaro), Sebastián Lerdo de Tejada asume la presidencia de la República para hacerse cargo de la misma, hasta que Porfirio Díaz asume después la primera magistratura por más de treinta años, y no será sino que por medio de un movimiento armado 
revolucionario y con la promulgación de la Constitución Política de los Estados Unidos Mexicanos de 1917, se genera un ambiente de aparente paz y respeto a la soberanía del pueblo, con la permanencia un partido hegemónico por más de setenta años en el poder, siendo hasta el año 2000 cuando se dio la alternancia en el ámbito del Poder Ejecutivo federal.

No obstante, a pesar de este pasado inmediato de sucesión política alternativa, y de los esfuerzos que realizan las instituciones electorales, los partidos políticos, las instituciones educativas y los medios de comunicación, aun no son factores suficientes para eliminar o al menos combatir en gran medida la pobreza tanto en nuestra entidad federativa como en México y en algunos países del mundo.

Esta realidad se suma a la diversidad de partidos políticos existentes, participes en las contiendas electorales que inciden en el hecho de que el triunfador de los comicios electorales no sea elegido por una mayoría absoluta, y por ende, se incurra en un escenario de inconformidades en no pocas ocasiones, impugnándose los resultados.

Esta situación se corrobora con lo que refiere Jorge Mario Lescierur Talavera, que cuando cita a Maurice Duverguer, nos dice:

[...] la legitimación del poder no es otra cosa que el hecho de que es reconocido por tal por los miembros de la colectividad, o al menos por la mayoría de ellos [...] la fuente única de legitimidad definido por el sistema de valores y de normas de la colectividad donde se ejerce y que exista un consenso en el interior de esta sobre dicho esquema. ${ }^{2}$

Considero prudente en este aparatado, hacer mención de estas circunstancias que se presentan en nuestra entidad federativa de Tlaxcala, con los resultados de las dos últimas elecciones locales que se han realizado, y donde se demuestra que no obstante el pluripartidismo, la influencia de los medios de comunicación, el grado de cultura que poseen las nuevas

2 NOHLEN, Dieter, "Voz: Elecciones", en Diccionario Electoral, Instituto Interamericano de Derechos Humanos, Centro de Asesoría y Promoción Electoral, Costa Rica, 1989. 
generaciones, entre otros factores, se sigue dando el fenómeno del abstencionismo, atribuido a diversas causas.

Una de ellas es porque los resultados obtenidos dependen de si es una autoridad administrativa o legislativa a la que se elige, será entonces que a la ciudadanía le interesa más participar por elegir a aquella autoridad con la que va a tener mayor relación y de la que considera obtener mayor apoyo para la solución de sus diferentes problemas económicos, de servicios públicos y de educación que los conduzcan a una mejor calidad de vida, a diferencia de aquella autoridad legislativa, de quien solamente recibirá orientación y gestoría, pero no recursos de manera directa, porque esa no es su función.

Otra razón es porque el candidato del partido al que pertenece, no responde a sus expectativas de superación o bien ningún otro candidato de los partidos contendientes. A su vez, está el medio social y geográfico en el que se desenvuelve el votante, o la no existencia de sanción por el incumplimiento del derecho de votar (como ocurre en Argentina), las deficientes administraciones anteriores que lo han defraudado en su confianza y algunos otros elementos que hacen que la ciudadanía distraiga su atención en otras actividades y se olvide de votar, de ejercer sus derechos y sus prerrogativas, las cuales están sujetas a una condición jurídica.

Ello no obstante que los derechos humanos se tienen desde que el ser humano ha nacido, como lo es el derecho a la vida y a su libertad, así como el derecho a que el Estado le proporcione seguridad y todas las condiciones indispensables para su realización y superación a través de un verdadero ejercicio y aplicación de la democracia.

\section{Legitimidad popular y democracia}

El término democracia en nuestro régimen es empleado de manera exhaustiva durante las campañas electorales para contextualizar la elección de las autoridades legislativas y administrativas.

Todo parece indicar que es una palabra o un concepto reservado exclusivamente para ser utilizado en un ritual político, en el cual por sus características peculiares, es ahí donde sólo puede causar impacto, efecto o resultado que un candidato pretende obtener entre sus simpatizantes, 
militantes y todos los ciudadanos que lo escuchan. Y de modo práctico, se representa durante sus eventos políticos, y tales actos, prácticas y objetivos consisten en convencer a la ciudadanía para que el día de la contienda electoral acuda a las urnas a depositar su voto en favor de su candidatura y así obtener el añorado triunfo. Pero una vez logrado éste, como por arte de magia desaparece el ideario de la ahora ya autoridad o servidor público, así como los compromisos contraídos durante la campaña; y aquel candidato optimista, visionario, accesible y entusiasta, se convierte en frio y calculador político, realista y reservado, técnico y moderado en su vocabulario, que evita relación con congregados masivos populares y prefiere las ceremonias oficiales, la comunicación con sus iguales y superiores jerárquicos. Sus compromisos de convivencia ya no son con sus representados, porque su investidura le implica dirigir su atención a asuntos de gran importancia con máximas autoridades, hecho que le impide atender problemas de su gente, por ser — supone- de ínfima importancia.

Este tipo de comportamiento es el que desmoraliza a la ciudadanía, que ilusionada acudió a las urnas con la esperanza de mayores expectativas de progreso que los conduzcan a mejores estadios de vida, y que al no darse, en posteriores contiendas electorales se refleja en abstencionismo o bien en cambio de militancia hacia otro partido político, lo que determina que los próximos candidatos se conviertan en nuevas autoridades con un menor número de votos, no alcanzando una mayoría absoluta, siendo así no debidamente legitimados en el poder.

Giovanni Sartori nos dice que "el poder es del pueblo", ${ }^{3}$ y se establece una concepción sobre las fuentes de la legitimidad del poder.

Para este efecto, Democracia quiere decir que el poder es legítimo sólo cuando su investidura viene de abajo, sólo si emana de la voluntad popular, lo cual significa en concreto si es en cuanto libremente consentido.

Tal aseveración tiene relación con lo que la Constitución General de la Republica establece en su artículo 39: "La soberanía nacional, reside esencial y originalmente en el pueblo, todo poder público dimana del

${ }^{3}$ SARTORI, Giovanni, ¿Qué es la democracia?, Editorial Patria, México, 1997. 
pueblo y se instituye para beneficio de éste. El pueblo tiene en todo tiempo el inalienable derecho de alterar o modificar la forma de su gobierno". Giovanni Sartori, nos indica "que existe democracia si el poder es legítimo, si emana de la voluntad popular, que si la designación de los dirigentes no proviene del consenso popular, no hay democracia". ${ }^{4}$

Esto implica que si el pueblo como soberano no participa legitimando a sus autoridades en las elecciones respectivas, no se está ante una verdadera democracia que genere como consecuencia gobiernos aceptados por la gran mayoría, que pueden llevar a cabal realización, planes y programas de trabajo que redunden en beneficios colectivos. Entonces, chasta cuándo las condiciones culturales, económicas y sociales serán las adecuadas para que en nuestra entidad y en el país entero se logre tener la mayoría absoluta de participación ciudadana en las elecciones populares?

Y no nada más eso, sino que nuestras normas electorales de igual manera establezcan los procedimientos y las formas, a efecto de exigir que una autoridad de elección popular sea legalmente reconocida, sólo si es legitimada en el poder por una mayoría absoluta de la ciudadanía, porque es la forma de participación ciudadana más conveniente para lograr el desarrollo económico sustentable de los pueblos, que genere a su vez la paz social debidamente consensada y duradera que permita a todo individuo su integra realización como profesional, empresario, político, comerciante, trabajador, y como ser humano parte de una familia, de una sociedad y de una nación.

En tal virtud, nuestros gobernantes, sus instituciones y órganos del poder deben acentuar su interés en el aspecto político electoral para evitar conflictos sociales de funestas consecuencias, situación que nos demuestra Roberto Bergalli y Eligio Resta, quienes al citar a Elías Canetti, nos dicen que "con cada voto la guerra se aleja, pero al mismo tiempo también se perpetúa”.

Los números cuentan como fuerza también en la elección de los diputados; la campaña electoral es ese reflejo ritual en el cual está permitido ofender, desvalorizar, denigrar políticamente al adversario, escarnecién-

4 Ibíd.

5 Ibíd. 
dolo, deslegitimándolo. Es obvio que durante el tiempo que señala el derecho electoral de nuestro país y en lo particular en Tlaxcala para realizar campañas electorales, los respectivos candidatos contendientes lo aprovechan para dar a conocer su ideología, sus proyectos políticos, su trayectoria política, cultural y profesional, recaudar inquietudes, sugerencias, advertir necesidades y contraer compromisos. Sin embargo, las leyes electorales no pueden evitar que este espacio de tiempo, también sea utilizado para denigrar al adversario, desvirtuar a los demás partidos políticos, confrontar a la ciudadanía, dividir criterios y opiniones, empleando la generalidad de las veces un discurso falaz, demagógico e incendiario que genera lacras y diferencias difíciles de superar en las sociedad, porque se convierten en secuelas que en cada periodo de elecciones se reavivan, se consolidan y se hacen más grandes y fuertes, conduciéndonos a la irreconciliación política entre los ciudadanos.

Canetti indica respecto de esta realidad negativa:

La metamorfosis de la guerra en guerra parlamentaria, el abandono de la violencia que consiste en la batalla confiada a los números, esto es lo que marca la diferencia. Cada voto aleja una agresión: pero, quien tome como juego esos números, quien los confunda, los falsifique, lo que hace es dejar nuevamente un espacio a la muerte sin darse cuenta de ello".

A pesar de todo lo benéfico que resulta lograr la máxima participación de la ciudadanía en la elección de sus gobernantes, de las fuertes inversiones económicas de los partidos políticos y que sus candidatos con el fin de obtener la aceptación del pueblo y alcanzar el triunfo anhelado, finalmente sólo se queda en un intento más, en una hazaña emprendida que se consolida parcialmente para el candidato triunfador en lo personal, pero en lo medular - que es politizar a los electores, concientizarlos de sus responsabilidades ciudadanas, para con su municipio, entidad federativa o país - realmente no se logra.

A esto debemos agregar que en los últimos tiempos, las elecciones tanto locales como federales siguen dentro del marco tradicional de acción perniciosa, donde lo que más se ha acentuado es la típica dádiva de la propaganda política, que en nada asegura al candidato — que por el 
hecho que el ciudadano lo acepte — sea ya una razón más que suficiente para obtener un voto a su favor.

$\mathrm{Al}$ no aplicarse la democracia sustantiva, la indiferencia política sigue manifiesta, al no reflejarse el compromiso con un gran sector de la ciudadanía, donde existe otra elevada proporción de las masas populares que prefieren el aislamiento político, autodenominándose apolíticos; del otro lado, para algunos ciudadanos les es cómodo condicionar su voto con base en la solicitud de mayores regalías, o al grado mismo de canjearlo por dinero, lo que se califica como corrupción política, costumbre de la que candidatos y partidos políticos perdedores se quejan al final de la jornada y en ese argumento justifican y ocultan la no aceptación de la autoridad electa por la mayoría de la ciudadanía.

Estas circunstancias nos dan motivo para asevera que no se puede hablar de una efectiva democracia representativa, sobre todo si la consideramos como nos la plantea Javier Patiño Camarena: "Democracia representativa es la forma de organización política en la que todos los ciudadanos tienen participación en la voluntad general, crean el Estado, conforman el gobierno y eligen a sus representantes". 6

Me parece importante destacar el texto "Forma de organización política en la que todos los ciudadanos tienen participación en la voluntad general...", porque surgen así interrogantes como las que siguen: ¿en realidad todos los ciudadanos tienen participación en las decisiones de beneficio general? o ¿todo individuo sabe a ciencia cierta lo que significa democracia? Obviamente que las respuestas a estas interrogantes las podemos encontrar a través de encuestas que efectuemos para tal fin; pero eso no es lo fundamental, sino más bien es el cómo erradicar esa indiferencia, apatía, conformismo, carencia de cultura; es necesario un correcto, interesante o motivante y adecuado empleo de los medios masivos de comunicación, para contribuir a la efectiva y real participación ciudadana, para que la ciudadanía sea debidamente representada en el marco político, derivando esta inercia en mejores administraciones y eficientes legislaciones por parte de nuestros gobernantes, desempeñando cabalmente

6 PATIÑO CAMARENA, Javier, Derecho Electoral Mexicano, UNAM, Instituto de Investigaciones Jurídicas, México, 1994. 
su función representativa, de la cual González Ibarra en su obra Epistemología, nos dice que "la función representativa está definida tanto por las prácticas políticas y sociales, y constituye una "representación electiva", sin que se pueda analizar fuera del sistema político en conjunto, bajo la condición de ser elecciones competitivas con respeto del libre voto y los procesos electorales.

La representación es un fenómeno complejo, que en su núcleo consiste en un proceso de elección de los gobernantes y de control sobre su obra, a través de la existencia de un marco jurídico que permite la participación ciudadana para elegir a sus gobernantes, mediante el libre voto en elecciones competitivas con la imperante necesidad de limitar a las autoridades en el poder y promover el cumplimiento de éstas con sus funciones de acuerdo a las facultades y obligaciones que la ley les señale, y así sean salvaguardados los derechos fundamentales de sus representados.

Al no darse estas circunstancias en nuestra entidad, se tiene el imprescindible deber por parte de todas las instituciones educativas, políticas y civiles, de fomentar la conciencia política en el joven ciudadano, la idea de fraternidad y solidaridad para con su sociedad, entidad y país, porque la personalidad de la ciudadanía no es solamente haber cumplido el requisito de la mayoría de edad, y así sentirse libre, emancipado, desligándose de ciertos valores y del vínculo familiar; por el contrario, es necesario hacer del joven ciudadano un ente social con mayor responsabilidad, participativo, propositivo, crítico, analítico, dinámico, que funde en la ciencia, la cultura y el trabajo su propio porvenir y el bienestar de los demás, que entienda la ciudadanía como "una capacidad de goce y ejercicio de los derechos políticos, de participación en la formación del poder en el Estado". ?

Es necesario hacer comprender a la ciudadanía que la democracia no es sólo el hecho de depositar en la urna el voto a favor de determinado candidato, o que la democracia única y exclusivamente se hace patente en la época de campañas y comicios electorales, sino que está siempre presente en nuestra vida política, cultural, económica y social, como una

${ }^{7}$ Ibíd. 
forma de gobierno, como sistema político y económico, como constante participación individual y colectiva del pueblo, en los diferentes campos productivos, con el fin de ser factor importante y trascendente de cambio, de prosperidad en general.

Debe convertirse la democracia en la razón para que el ciudadano aprecie sus vínculos nacionales, para que tenga pleno conocimiento de su historia nacional, su cultura, tradiciones, que acepte sus recursos humanos y materiales, cuyo valor y capacidad los enfoque con la tendencia de favorecer a los demás como a sí mismo, que busque en la colectividad la armonía y la cordura que permitan superar todas sus frustraciones o problemas, que no recurra a los vicios y a la delincuencia, y sí por el contrario, que contribuya a la conformación de un ambiente englobado por la seguridad y paz social, crear un Estado lleno de oportunidades donde no existan diferencias de raza, credo religioso, ideología política, clase social.

En la democracia se debe buscar que las diferencias sean resueltas conforme a las normas dispuestas expresamente para tal fin, que se aprenda a vivir en la diversidad de criterios y opiniones, convergiendo en los objetivos comunes y luchando unidos por lograrlos sin mezquindades -que únicamente nos conducen a confrontaciones, al retroceso económico, cultural, político y social.

\section{Renovación del poder público en la democracia}

Como ya se dijo, la democracia representa un término que a través de la historia de los diversos sistemas políticos, se ha utilizado no sólo por gobiernos liberales, sino también por otros que no han reunido los requisitos que impone este vocablo (no olvidemos la desaparecida República Democrática Alemana, que al igual de otras naciones, en su forma de gobierno no era republicano, y mucho menos democrático).

Este término fue utilizado por primera vez por los griegos, de ahí que etimológicamente el término democracia "proviene de dos palabras grie- 
gas: demos que significa pueblo y cratos, autoridad; expresa la idea de que el poder pertenece al pueblo". 8

Felipe Tena Ramírez, citando a Aristóteles, manifiesta: el poder de mando o de gobierno puede residir en un solo individuo, en una minoría o en una mayoría; en cada uno de estos fundamentos del gobierno distinguía Aristóteles una forma pura y una forma impura.

Cuando el gobierno reside en un solo individuo, tenemos la forma pura de la "monarquía"; si ese individuo emplea el poder de que dispone en beneficio de todos; y es la forma impura de "tiranía", si ese individuo utiliza el poder en beneficio exclusivo de sí mismo o de sus favoritos. Cuando el gobierno reside en una minoría, existe la forma pura de la "aristocracia" si la minoría usa el poder en beneficio de todos, y la forma impura de la "oligarquía", si el poder sólo beneficia a la minoría que lo detenta.

Por último, cuando el poder lo usufructúa la mayoría de la colectividad, resulta la forma pura de la "democracia" si ese poder favorece a todos por igual; la forma impura de la "demagogia", si se aplica tan solo en servicio de los desposeídos.

Mucho tiempo después de los pensadores de la antigüedad clásica, Abraham Lincoln se refería también a la democracia como el gobierno del pueblo, por el pueblo y para el pueblo. Hoy el término democracia se sigue utilizando en diferentes disciplinas, pero sobre todo en la política, cuyo significado es posible sintetizarlo como la intervención del pueblo en el gobierno. Sin embargo, la palabra democracia no es posible que exista aisladamente, pues resulta necesaria la vinculación con otros conceptos como el de soberanía y el de república como forma de gobierno.

De ahí que la democracia sea parte substancial de los regímenes en los cuales las principales autoridades públicas no sean vitalicias, sino de renovación periódica, consultando para tal efecto la voluntad popular. "La esencia de esta forma es que los funcionarios cambien con frecuencia,

8 BERLín VALENZUELA, Francisco, "Los Sistemas Electorales", en Memoria del Primer Congreso Internacional de Derecho Electoral, vol. II. UNAM-Universidad Veracruzana, Veracruz, 1991. 
ejerciendo sólo temporalmente sus cargos; por lo común impera en dicha forma la democracia"?

Esta voluntad popular se torna vigente, desde el punto de vista jurídico, cuando participan los ciudadanos, ya sea por medio del sufragio, de los partidos o agrupaciones políticas, o bien, como candidatos. Por otra parte, es importante señalar que en la democracia no existe la unanimidad, sólo la voluntad de las mayorías. De igual manera, una vez que se hayan hecho efectivos los derechos político-electorales por parte de los ciudadanos, las autoridades legalmente establecidas desempeñarán sus actos unilaterales, coercitivos e imperativos frente a todos aquellos que habiten en el territorio del Estado correspondiente, con independencia de la edad, el sexo, el color, la religión, etcétera.

En este contexto, no todos los ciudadanos elegimos a las autoridades que han de gobernarnos, pero sí todos los habitantes estaremos subordinados a ese poder. Sin embargo, la democracia es y seguirá siendo la forma por excelencia por medio de la cual se hacen efectivos los derechos político electorales por parte de los ciudadanos. De ahí que los artículos 39 y 40 de nuestra Constitución se encuentren estrechamente vinculados; el artículo 39, por lo que se refiere a la soberanía depositada en el pueblo y el 40, porque "Es voluntad del pueblo mexicano constituirse en una República representativa, democrática..."

\section{Democracia social}

Al celebrarse las elecciones de los gobernantes de nuestra entidad federativa, se genera en la ciudadanía tlaxcalteca un elevado porcentaje de expectativas de progreso, se despiertan esperanzas, se forjan metas, se plantean propuestas, se elaboran conjeturas y un gran interés por conocer las estrategias, mecanismos, planes y medios para superar los problemas de educación, económicos y sociales que afectan a la colectividad.

Es el momento en el cual también la gente se clasifica de acuerdo a su estatus social, se acentúa y se acepta la estratificación, porque el ciudadano considera que al darle a conocer al candidato sus carencias o su precaria situación económica, aumentan sus probabilidades de recibir

\footnotetext{
${ }^{9}$ Ibídem.
} 
apoyos económicos o materiales, mismos que les permitan incursionar a la movilidad social para escalar otro peldaño dentro de la pirámide en la que se ubican las clases sociales, y por qué no; aunque de manera utópica, pensar remotamente en alcanzar la igualdad con los más encumbrados de su ámbito social.

Es una de las razones por las cuales el ciudadano de escasos recursos participa, pues desea ser parte de todo el conglomerado, asegurar su integración a su estrato y a la sociedad en general, para pugnar y alcanzar la igualdad entre sus congéneres. Sartori al respecto nos dice que la "Democracia social revela una sociedad cuyos hechos exigen a sus propios miembros verse y tratarse socialmente como iguales". ${ }^{10}$

En efecto, este tipo de democracia es el que debe mover a las masa populares, participar responsable y activamente en las contiendas electorales y hacerlas más competitivas, más congruentes con la realidad, induciendo al ciudadano hacia su propia formación integral, y de esta manera su acción se refleja madura, vertical, fundamentada y visionaria; por el contrario, no se le debe enajenar y dominar por la pasión, el encono, la envidia, y sus frustraciones, sin reflexionar acerca de las ideologías, principios, valores religiosos, morales, familiares, que son los que contribuyen a consolidar la paz en las sociedades, haciendo posible la convivencia sin importar las diferencias de raza, credo, posición social, sexo, nacionalidad, etc., sino ver por el desarrollo económico, científico y tecnológico de su entidad y país, abocándose cada uno de sus integrantes a las tareas encomendadas, produciendo los satisfactores que les permitan superar sus necesidades, incurriendo en el bienestar social.

\section{Enfoque teórico de la democracia}

El ejercicio de la democracia es un derecho que permite a la sociedad construir un consenso de ideas y opiniones, a través de la formulación de preferencias y la participación activa dentro del Estado.

En otras palabras, la democracia es la máxima expresión de la participación del pueblo en el gobierno, donde los habitantes de un determinado país se organizan para intervenir en la toma de decisiones, que les

10 SARTORI, Giovanni, ¿Qué es la..., op. cit. 
permite participar en la vida política del Estado; por su etimología el origen de la palabra democracia, se derivada de dos vocablos del griego que son "demos" que significa pueblo y "cratos" que significa autoridad o poder. Por consiguiente y según su etimología se define a la democracia como el gobierno del pueblo. ${ }^{11}$

Norberto Bobbio, tratadista italiano, construye una definición mínima de la democracia, según la cual las personas pueden decidir y establecer su forma de gobierno; por régimen democrático se entiende entonces al conjunto de reglas y de procedimientos para la formación de decisiones colectivas, en el que es prevista y facilitada la más amplia participación posible de los interesados. ${ }^{12}$

Thomas Hobbes al respecto establece la naturaleza del representante para definir su gobierno, y expresa que cuando el representante es un hombre, entonces el gobierno es una monarquía, cuando es una asamblea de todos cuantos quieren concurrir en ella, tenemos una democracia o gobierno popular, y cuando la asamblea es de una parte solamente, entonces se denomina aristocracia.

Pedicone de Valls, al resumir en su libro La evolución de la democracia desde la antigüedad hasta la democracia moderna, indica que ha salido fortalecida la democracia como autogobierno del pueblo, que concibe al hombre y a la sociedad dentro de un supuesto racional que lo hace convivir en un orden voluntariamente establecido, y cuya esencia radica en las amplias dimensiones de la libertad y la igualdad, rechazando cualquier forma de dominación, injusticia y gobierno arbitrario. ${ }^{13}$

Por consiguiente, la democracia ha ido acoplándose como un mecanismo viable para las sociedades grandes y modernas, y de conformidad con el elemento básico de la democracia que es el pueblo, los autores han clasificado a la democracia por la forma de participación del pueblo en:

11 CABANELLAS DE TORRES, Guillermo, Diccionario Jurídico Elemental, Editorial Heliasta, Buenos Aires, 2005. p. 115.

12 BOBBIO, Norberto, La teoría de las formas de gobierno en la historia del pensamiento político (Trad. José Fernández), Fondo de Cultura Económica, México, 1987. p. 37.

${ }^{13}$ DE VALLS, Pedicone, Derecho Electoral, Editorial La Rocca, 2001. p. 24. 
democracia directa, indirecta o representativa y semidirecta, clasificación que vamos a describir.

\subsection{Democracia directa}

En primer lugar, la democracia directa como forma de gobierno viene desarrollada por los atenienses en el siglo V, a. C.; la democracia directa o antigua, se basaba en un sistema de autogobierno; por tal razón, sólo existe la participación del pueblo sin necesidad de representantes. Es Rousseau uno de los defensores de la democracia directa por su pensamiento sobre la «soberanía popular», que es inalienable e indivisible, por lo que considera que "la soberanía no puede ser representada, por la misma razón que no puede ser enajenada, consiste esencialmente en la voluntad general, y la voluntad general no se representa; es ella misma o es otra, no hay término medio".

Aquella reflexión nos permite establecer que la democracia directa niega la existencia de la representación, porque ésta sólo traería sumisión del pueblo. La democracia y representación resultan dos términos incompatibles, y es por ello que el pueblo es el que ejerce directamente las funciones estatales, porque sin el pueblo todo acto que se desarrolle sería ineficaz e ilegítimo.

En conclusión, la democracia directa, siendo un sistema puro, no fue un sistema de organización política ideal, existieron varias limitaciones pues las asambleas eran libres para cualquier varón adulto que fuera ciudadano y mayor de veinte años. Sin embargo, es un ejemplo para las sociedades actuales y punto de partida de los mecanismos de democracia semidirecta que hoy conocemos. Lo que para ellos fueron las votaciones a mano alzada, para nosotros son los antecedentes al sufragio activo, donde lograron establecer la participación popular y buscaron el bien común que es el objetivo de una democracia; por ello, la democracia directa sigue siendo objeto de estudio en el presente.

En contraposición a la democracia directa, existe la democracia indirecta o representativa, siendo la clasificación de democracia más adoptada por los países en la era moderna. 


\subsection{Democracia representativa o indirecta}

En segundo lugar, la democracia representativa o indirecta, es aquella que como su nombre lo indica, las ciudadanas y los ciudadanos de un país no desarrollan directamente el ejercicio del poder, sino que delegan ese poder a sus representantes. Varios tratadistas consideran a la democracia representativa como la única forma de progreso de las sociedades, porque si bien la democracia directa es un sistema de autogobierno ideal, en la práctica la representación ha permitido la estructura política y jurídica de un Estado democrático; así lo afirma Stuar Mill, al decir que "el tipo ideal de un gobierno perfecto no puede ser otro que el representativo". ${ }^{14}$

Duverger define a la democracia representativa como "el sistema político en que los gobernantes son elegidos por los ciudadanos y considerados de esta forma como sus representantes". Sin embargo, para elegir a los representantes es necesario un sistema de elecciones y construir normativa electoral.

Pedicone de Valls analiza que la democracia representativa sería entonces el sistema político que combina la libertad individual y el respeto a las diferencias con las necesidades que impone la organización racional de la vida colectiva. Por ello, la democracia moderna sólo puede funcionar como democracia representativa; y representación significa que el ciudadano mediante el instrumento de elecciones, delega el poder político por un cierto tiempo, en determinadas personas y procedimientos. ${ }^{15}$

La democracia representativa surge, primeramente al no ser posible aplicar la democracia directa y al observar al pueblo en su conjunto como una nación; esto último es aporte que se dio durante la Revolución Francesa, lo que llamamos «teoría de la soberanía nacional». Al respecto, el tratadista Hernán Salgado Pesantes analiza la teoría de soberanía nacional y dice "Al pueblo se lo concibe como una nación y no como una comunidad de personas individuales"; en correlación, Sieyés, ideólogo del siglo

14 BIDART CAMPOS, Germán José, Derecho Político, Editorial Aguilar, Buenos Aires, 1972. p. 328.

${ }^{15}$ DE VALLS, Pedicone, Derecho Electoral..., op. cit., p. 41. 
XVIII, habla sobre la "soberanía que reside en el pueblo como un cuerpo estable llamado nación”.

Y según esta teoría, la nación es concebida como algo distinto de la simple suma de los individuos que la componen, es una entidad objetivada, fruto de su reunión, no de su adicción:

$\mathrm{Y}$, por ello, la soberanía nacional no es tampoco el resultado de sumar voluntades individuales. Puede ser expresada por órganos no democráticos en su formación y, en general, no es preciso que concurran a determinarla todos los ciudadanos; la teoría justifica restricciones sociales al derecho de sufragio, para que sólo elijan al órgano formador de la voluntad nacional quienes «merecen» hacerlo en atención al concepto normativo de $\mathrm{Na}$ ción.

Concluimos por medio de la teoría de la soberanía nacional que la nación no tiene voluntad por sí misma, y es necesario que la colectividad exprese sus intereses generales, para que la voluntad colectiva sea el fundamento de la autoridad; a esto se le llama soberanía y la soberanía que radica en el pueblo permite elegir representantes que son los que gobiernan el país.

Sin embargo, aunque varios autores optan por la democracia representativa como el mejor sistema de gobierno posible, existen algunos Estados que critican esta forma de democracia, porque la consideran como una democracia solamente teórica y en la práctica no existe una participación del pueblo que es el titular de la soberanía. Los gobernantes se alejan de la voluntad del pueblo y lo excluyen de las decisiones.

Con estas consideraciones, encontramos que existe una doble necesidad: primeramente, el poder controlar a los representantes de elección popular, para que no se alejen de la voluntad colectiva, y el poder desarrollar formas o mecanismos que les permitan a los ciudadanos participar activamente de la estructura del Estado, de donde surge la tercera clasificación de las formas de democracia, que muestra un sistema mixto, conocido como democracia semi-directa. 


\subsection{Democracia semi-directa}

La democracia semi-directa es aquella democracia híbrida, que consiste en la combinación entre democracia directa y democracia representativa, sin que se contrapongan, y posibilita una mayor intervención del pueblo en los asuntos de interés general, dado que tanto la democracia directa y representativa paulatinamente han ido limitando la participación del pueblo en la estructura política y jurídica.

Pedicone de Valls comenta sobre la democracia semi-directa, estableciendo que esta democracia posibilita que el pueblo intervenga en la actividad legislativa, gubernamental y constitucional, porque en la práctica de la democracia representativa la participación popular cada vez se iba disminuyendo y "los partidos políticos desplazaron a los ciudadanos quienes quedaron limitados". ${ }^{16}$

Bajo estas condiciones, la democracia semi-directa dio lugar a diferentes instituciones que permiten la participación ciudadana, y mediante estas instituciones los ciudadanos se organizan, deciden y presentan peticiones al Estado de forma directa y conforme a los requisitos que determinen la Constitución y las leyes.

Los mecanismos de democracia semi-directa en algunos países se dividen en: iniciativa popular normativa, el referéndum, la consulta popular y la revocatoria del mandato; éstos impulsan además la configuración progresiva de nuevos espacios que posibiliten el ejercicio directo del poder ciudadano de acuerdo con la Constitución.

A estos mecanismos que permiten una mayor participación de los ciudadanos y que mejoran la democracia representativa, es lo que el tratadista Hernán Salgado Pesantes llama "democratización del gobierno representativo". ${ }^{17}$

Aquella reflexión nos permite desarrollar las siguientes ideas: primero, se reconoce toda forma de organización de la sociedad, y segundo, todos los miembros de la organización pueden participar democráticamente

16 Ibídem, p. 24.

17 SALGADO PESANTES, Hernán, Lecciones de Derecho Constitucional, Ediciones Legales, Quito, 2004, p. 153. 
sobre los asuntos de interés público, y sobre todo, defender los derechos por el bien común.

\section{Conclusiones}

Como ciudadano, considero que hay la percepción de que una vez que en las elecciones finaliza el proceso de votación, hasta ese momento también culmina la importancia de la participación ciudadana, al haberse conocido los resultados aritméticos del total de los sufragios emitidos en favor de un candidato del partido triunfador y que en lo sucesivo empezará la tarea exclusiva del nuevo gobernante, servidores públicos, autoridad, mandatario, o representante según se le mencione de acuerdo al lugar, al cargo, a la comunidad, Municipio, Entidad o Distrito, de acuerdo a los modismos y regionalismos con los que la sociedad se exprese, y en consecuencia, crezcan las alternativas de trabajo, superación, educación, salud, seguridad, justicia, bienestar social, etc.

Sin embargo ante los resultados que se han presentado en algunos procesos electorales, me he dado cuenta de lo importante que es el escrutinio, porque de él depende que verdaderamente se respeten, en primer término, la voluntad del ciudadano manifestada en la preferencia de su candidato o partido; segundo, que el cómputo sea el real y no se alteren o modifiquen las cantidades ciertas, y por último, que los órganos encargados del cómputo y escrutinio sean totalmente imparciales, justos y honestos para que no quede lugar a duda del triunfo de cierto candidato o partido, pues como se ha comentado mucho respecto de los resultados de las elecciones presidenciales de 1988 o las de 2006, dejaron entrever que estuvieron viciadas o definidas por el fraude electoral, recientemente en 2016, las elecciones de gobernador de Tlaxcala, de la misma manera en que se presentó la sombra del fenómeno de la corrupción. Todo esto, atendiendo a la cita que hace Beatriz Franco, de que "La oposición puede ganar las elecciones, pero los escrutinios los gana el gobierno" o dicho en otras palabras: "Quien escruta, elige".

Entonces, resulta necesario que las elecciones no dependieran de los gobernantes en turno, para que en algunos ciudadanos no desaparezca el deseo y convicción de participación en pro de la satisfacción de sus aspiraciones por una mejor calidad de vida, de la certeza de que el hecho de 
simpatizar con un candidato o un partido político le garantice el respeto a su triunfo, y a la vez se genere en toda la población un ambiente de estabilidad política, económica y social, porque en algunos otros ciudadanos, cuya participación estuvo basada en la esperanza de que con el nuevo gobernante a quien se apoyó, le serán resueltos muchos de sus problemas, de sus carencias, de sus expectativas de crecimiento y desarrollo social, y habrá también quienes, al considerar que las elecciones no fueron limpias, en ellos existirá la frustración, la decepción y el rechazo a las nuevas autoridades electas por considerar que no son las idóneas, y que además no son capaces o no tienen la ideología adecuada para poder gobernar y ser factores de cambios trascendentales que se reflejen en progreso de la colectividad.

Tal parece que a partir del momento en que un nuevo gobernante inicia su periodo, allí termina la participación del ciudadano en la toma de decisiones fundamentales en la vida democrática de una comunidad, municipio o entidad federativa, porque supone que a partir de la nueva administración, solamente a ella le asiste la facultad de decidir dónde, cómo y cuándo aplicar los recursos económicos y materiales, que primordialmente en eso consiste su función.

Reitero, sólo la democracia se logrará a través de la participación consciente de los ciudadanos y del honesto, justo y responsable ejercicio del poder por parte de nuestros gobernantes, y si bien este documento se remite únicamente a un estudio teórico y conceptual, también se plantea con el objetivo de sentar las bases de un verdadero ejercicio y comprensión de la democracia y más aún, de fomentar un cultura electoral de participación activa y decidida de los ciudadanos en las decisiones torales del bienestar social, con el afán de generar en la sociedad en general y particularmente en Tlaxcala, una verdadera participación.

Es necesario educar en materia de derecho electoral a la niñez y juventud desde temprana edad, en las instituciones de educación básica y hasta la media superior, en virtud a que el artículo 72 de la Ley General de Educación permite que las organizaciones de la sociedad civil, asociaciones de padres de familia y maestros, cuyo objeto social sea la educación, ante el Consejo Nacional de Participación Social en la Educación y ante el Consejo Estatal, podrán opinar en asuntos pedagógicos, planes y 
programas de estudio, y proponer políticas para elevar la calidad y la cobertura de la educación, para que se incluya en los programas de estudio respectivos una materia de derecho electoral, en la que se impartan a los estudiantes los derechos, obligaciones y prerrogativas del ciudadano, así como cuáles son las leyes y organismos encargados de las elecciones populares para elegir a sus autoridades y representantes, y de esta manera, cuando la ahora niñez y juventud alcancen la mayoría de edad y deban participar en elecciones populares, lo hagan con plena conciencia, con firme convicción, identidad nacional, estatal, municipal y comunitaria, con cabal patriotismo y se combata la compra de votos, la corrupción, la movilización, la cultura de la dádiva, y la desleal y desigual competencia entre los candidatos de los diferentes partidos políticos participantes en las respectivas contiendas electorales, con Educación Cívica y Ética política, para generar una cultura lo suficientemente amplia, de convicción

- ntidad social y compromiso con la gente para alcanzar el Dien comun.

Se debe convertir al ciudadano en un verdadero evaluador de sus representantes políticos, y a través de un análisis responsable, fundamentado, sistemático, científico y experimental, poder emitir un juicio crítico de su función desempeñada durante su mandato o representación, con un criterio amplio, consciente, imparcial y con pleno conocimiento jurídico político, para decidir si es que lo considera en bien de la sociedad, reelegir a sus representantes, o de lo contrario, optar por el rechazo, en virtud de que, conforme a la evaluación emitida respecto al desempeño de sus representantes, determine el ciudadano que no es o son merecedores de ser reelectos para el periodo inmediato subsecuente, además de que participe de los beneficios a los que el Estado está obligado para su causa y exija el cumplimiento cabal de sus gobernantes de las funciones para las que fue electo y considere que la alternancia es una opción de mejora. 


\section{Fuentes de información}

BERLÍN VALENZUELA, Francisco, "Los Sistemas Electorales”, en Memoria del Primer Congreso Internacional de Derecho Electoral, vol. II. UNAM-

Universidad Veracruzana, Veracruz, 1991.

BIDART CAMPOS, Germán José, Derecho Político, Editorial Aguilar, Buenos Aires, Editorial Aguilar, 1972.

BOBBIO, Norberto, La teoría de las formas de gobierno en la historia del pensamiento político (Trad. José Fernández), Fondo de Cultura Económica, México, 1987.

CABANELLAS DE TORRES, Guillermo, Diccionario Jurídico Elemental, Editorial Heliasta, Buenos Aires, 2005.

Constitución Federal de los Estados Unidos Mexicanos de 1824, en Antecedentes históricos y Constituciones Políticas de México, Secretaría de Gobernación, México, 2010.

Constitución Política de la República Mexicana de 1857, en Antecedentes históricos y Constituciones Politicas de México, Secretaría de Gobernación, México, 2010.

Constitución Política de los Estados Unidos Mexicanos de 1917, en Antecedentes históricos y Constituciones Políticas de México, Secretaría de Gobernación, México, 2010.

DE VALLS, Pedicone, Derecho Electoral, Editorial La Rocca, 2001.

NOHLEN, Dieter, "Voz: Elecciones", en Diccionario Electoral, Instituto Interamericano de Derechos Humanos, Centro de Asesoría y Promoción Electoral, Costa Rica, 1989.

PATIÑO CAMARENA, Javier, Derecho Electoral Mexicano, UNAM, Instituto de Investigaciones Jurídicas, México, 1994.

SALGADO PESANTES, Hernán, Lecciones de Derecho Constitucional, Ediciones Legales, Quito, 2004.

SARTORI, Giovanni, ¿Qué es la democracia?, Editorial Patria, México, 1997. 